\title{
Practice update Get prepared for an emergency: An infographic
}

\author{
Blake, D. ${ }^{1}$, \\ Miller, A. ${ }^{2}$ \\ Rampton, A. $^{2}$ \\ 1 School of Psychology, Massey University, New Zealand. \\ 2 Wellington City Council, Wellington, New Zealand. \\ (C) The Author(s) 2017. (Copyright notice)
}

\author{
Author correspondence: \\ School of Psychology \\ Private Box 756 \\ Wellington 6140 \\ New Zealand \\ Email: D.Blake@massey.ac.nz \\ URL: http://trauma.massey.ac.nz/issues/2017-1/AJDTS_21_1_Blake.pdf
}

\section{Abstract}

Effective preparedness messages increase human capacity to prepare, respond and minimise harm during an emergency. The purpose of this study was to highlight the development of a pictorial infographic resource for earthquake and other emergencies for older people, people with mobility issues and people with literacy concerns in Aotearoa/New Zealand. A case study methodology was used to enable an in-depth description of the processes involved in designing, developing and disseminating the infographic. Case studies provide a medium to represent communitysituated knowledge and expertise. They value context, specificity and lived experience. The second two authors drove the initiative, and project managed the production of the infographic. The first author conducted a semi-structured interview with the other two authors to garner details of the process. This interview was transcribed and the case study outline was crafted. The authors went on to produce this paper collectively. The outcomes of this case study include recommending that a multidisciplinary approach be used to engage a range of stakeholders, to produce suitable preparedness messages for a range of audiences. Designing preparedness resources necessitates an iterative method and collective decision-making by relevant stakeholders. International best-practice guidelines provide evidence to ensure suitable resources are produced and gaps in knowledge identified, so that emergency preparedness is accessible for all.
Keywords: Preparedness, emergency management, infographic, earthquake, disability, community

This study showcases the development of an infographic to increase awareness about earthquake and emergency preparedness for diverse communities within Aotearoa/ New Zealand, and more widely. The global increase in disasters is a constant reminder of the need to adequately prepare. For instance, the 2015 Nepali earthquake killed, injured, and displaced thousands of people who were left without access to drinking water or food. Situated in Southern Asia with a population of approximately 26.4 million, Nepal has been plagued by infectious disease outbreaks as it struggled to rebuild destroyed communities and infrastructure (Basnyat et al., 2015). The Canterbury earthquake sequence of 2010 and 2011 was a stark reminder of the earthquake risk inherent to Aotearoa/New Zealand, an isolated country situated in the southwest of the Pacific Ocean with a population of approximately 4.7 million (Statistics New Zealand Tatauranga Aotearoa, 2016). The major February 2011 Christchurch earthquake (magnitude 6.3) killed 185 people, injured many more and caused significant infrastructure damage (New Zealand Police Nga Pirihimana o Aotearoa, 2012).

Aotearoa/New Zealand is located on the Australasian and Pacific tectonic plate boundary, and the capital city of Wellington sits atop a number of active geological faults, making it particularly prone to earthquakes (GNS Science Te Pū Ao, 2016). Consequently, people of Wellington are encouraged to prepare for earthquakes because of potential social, economic and health impacts including death, injury, geographical dislocation, damage to property, and psychosocial distress. The recent disasters experienced in Nepal, Canterbury, and elsewhere emphasise the importance of increasing human capacity to prepare and respond to an emergency to help safeguard against potentially serious harm.

Preparedness strategies occur at the reduction, readiness, response and recovery phases of a disaster. They enable people to identify and eliminate risks, develop competences, save lives and regenerate communities as they rebuild after an emergency strikes (Ministry of Civil Defence and Emergency 
Management, 2015; Paton, 2003). To encourage preparedness, targeted self-help programmes and public marketing campaigns aim to inform and educate. Community collaboration and engagement concerning preparedness aims to increase community knowledge to help overcome barriers that can hinder people from preparedness activities. Education strategies are disseminated through various print and social media sites, television and radio channels and public discussion domains. Additionally, scholarly research enables agencies and communities to evaluate the effectiveness of preparedness communication and action. This helps to produce preparedness knowledge, and enables political advocacy to reduce poverty and support minority groups (Frumkins, 2011).

With an understanding of the necessity of both academic and practical work and effectual preparedness messaging, this paper presents a case study outlining the way in which two of the authors, Anna-Marie Miller and Angela Rampton, from the Wellington City Council Neighbourhood and Community Networks team,

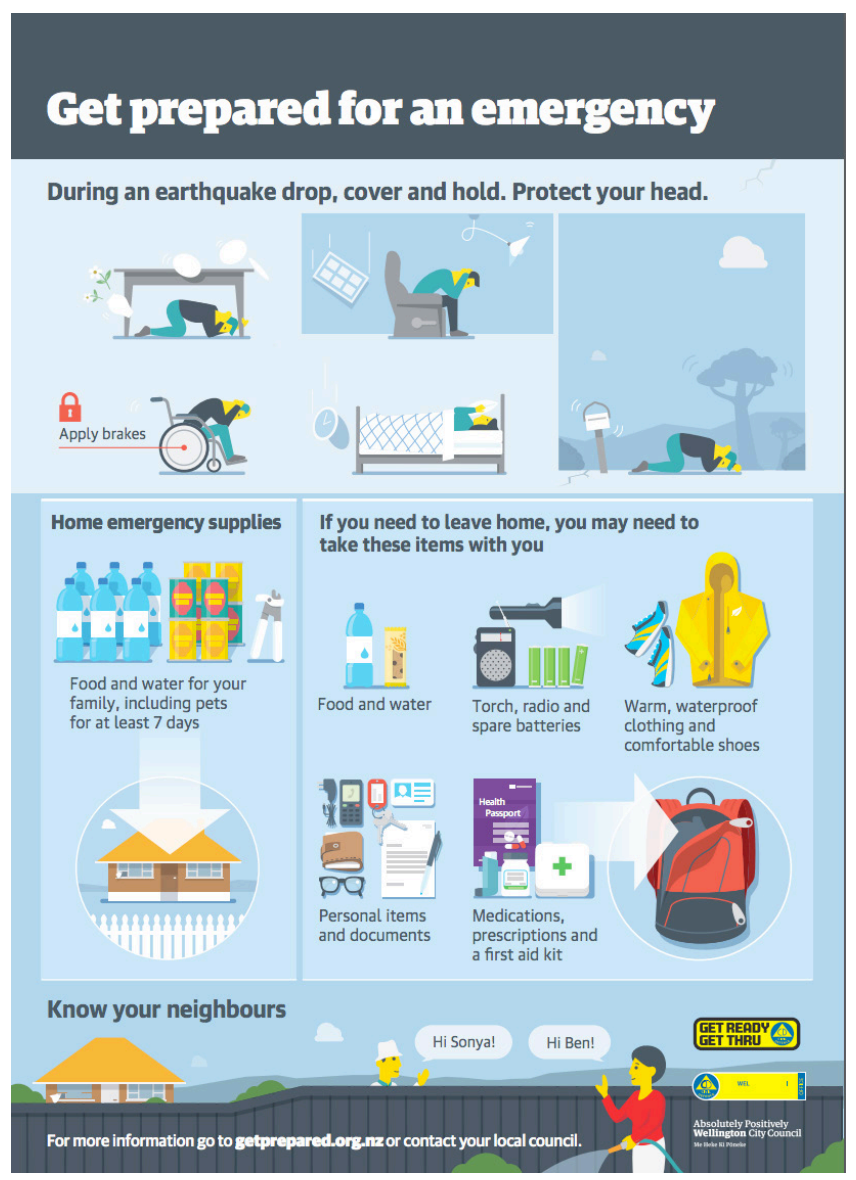

Figure 1. Get Prepared for an Emergency infographic. Reproduced from Get Prepared for an Emergency (p.1) by A. Miller \& A. Rampton. Copyright 2016 by Wellington City Council. Reproduced with permission. produced a targeted infographic signifying what to do when an earthquake hits and how to more generally prepare for a disaster. This infographic is shown in Figure 1. Anna-Marie and Angela have a neighbourhood and community development focus in their roles with the Wellington City Council. Anna-Marie is a Community and Neighbourhood Advisor and Angela is a Neighbourhood Development Coordinator.

\section{Context for infographic}

Since the Canterbury earthquake sequence of 2010/2011, earthquake preparedness messages have been prolific within Aotearoa/New Zealand. The standard message advises people to drop, cover and hold when an earthquake happens (Ministry of Civil Defence \& Emergency Management, 2015). More specifically, when in a building, people are advised to only take a few steps before dropping to the ground because large earthquakes can produce such severe shaking that people are thrown to the ground. The recommendation is to quickly find cover under sturdy furniture, like a table or desk. Holding onto a sheltering object provides protection and stops it from shaking away, while crouching over or getting into a ball position protects the body's main organs (Ministry of Civil Defence \& Emergency Management, 2016a).

A study by Johnston et al. (2014) found that two-thirds of the injuries from the Aotearoa/New Zealand Canterbury earthquake sequence were caused by the primary shaking. However the actions people took during the primary shaking and aftershocks also led to injuries: 51.3\% Darfield; $19.4 \%$ Christchurch. Where people are and what they do during an event influences injury risk. The Aotearoa/New Zealand Ministry of Civil Defence and Emergency Management (2016a) contend that most deaths and injuries during an earthquake occur due to falling objects, flying glass and collapsing walls and that drop, cover and hold reduces this risk.

Despite the drop, cover and hold message being functional for many, it assumes homogeneity because there are pockets of people who cannot effortlessly drop, cover or hold. While the drop, cover and hold message provides information on what to do immediately should an earthquake hit, it is not fit for purpose for some people (Paton, 2003). Groups that have trouble responding in an emergency situation include older adults and people with limited mobility (Tuohy \& Stephens, 2012). People with mobility issues have anxiety about not being able to drop to the ground and, if they can get to the ground, 
they worry they cannot get up again or that they might injure themselves in the process.

This situation was highlighted for Angela, during the 6.5 magnitude Seddon earthquake that affected Wellington in 2013. This earthquake caused minor injuries to four people, liquefaction, damage to buildings, and interruptions to Wellington traffic and human infrastructure (Hancox, Perrin, Archibald, Misra, \& Cousins, 2013). At the time, Angela had a colleague on the sixth floor of her Wellington workplace who required a wheelchair for mobility. Angela reported that while able-bodied staff dropped under their desks as the earthquake struck, the colleague had to remain in her wheelchair and could not seek cover. Evacuating the building was also difficult for her colleague. Lifts could not be used so an evacuation chair was necessary. Since the World Trade Centre disaster in 2001, and with the increase in disabled people in the workforce, fire safety communities worldwide are reformulating evacuation strategies to include mobility impairment. Movement speeds and egress movement data are now being collected, although research remains scarce. Ongoing research that accounts for evacuation diversity is essential to enable engineers to understand time required for safe egress in a more inclusive way (Kuligowski, Peacock, Wiess, \& Hoskins, 2013).

Other barriers to earthquake preparedness were brought to Anna-Marie's and Angela's attention when they were approached by community organisations frustrated by the lack of simple, coherent and easily understandable information on what to do in an earthquake. It became apparent to them that groups who struggled with the standard 'get prepared' message were culturally and linguistically diverse and had poor command of the English language. One humanitarian group told AnnaMarie and Angela that people struggle with literacy even in their native language. In such circumstances, people cannot sufficiently prepare survival kits because they cannot understand what is required of them. Some of the existing preparedness resources are over 10 pages long, or involve navigating intricate websites (see Ministry of Civil Defence \& Emergency Management, 2016a). It seemed that users felt like it is too hard to get prepared. Krum (2014) argues that when people are overloaded with large amounts of data it is difficult to filter nonessential information, focus on the relevant material and remember significant points. This is concerning when the information is potentially life-saving. Trying to assimilate an ever expanding stream of knowledge produces a form of anxiety, especially when people are aware that they do not understand information that they really need to know (Cairo, 2013; Wurman, 2000).

Understanding vulnerability characteristics, as argued by Paton and Johnston (2001), is important for the development of appropriate risk reduction strategies. People are heterogeneous, so identifying at risk groups and their relationship to the potential hazards enables targeted information that assists in mitigating risk. AnnaMarie and Angela realised they needed to produce a suitable resource for a range of older people, people with mobility issues, and for people with literacy concerns.

\section{Method}

\section{Design}

A case study framework was used to produce this paper because it enabled an in-depth investigation of the infographic project. As argued by Yin (2014), case studies explore contextually embedded phenomena. Case studies support community-situated knowledge and expertise, and enable community initiatives to be narrated through the lived experiences of community members. Often misunderstood, it is claimed that case study methodology is problematic because it fails to build theory, lacks generalisability, and represents biased researcher knowledge (Flyvbjerg, 2011). However, the current paper values specificity and lived experience, while resisting a reductionist, objective and decontextualized lens. Following Hays (2004), this work depicts the commitment and energy taken to produce community capacity and exemplifies the importance of practitioner work.

\section{Procedure}

To elicit the women's experiences, interviews were conducted in a manner akin to standpoint research. Standpoint epistemology privileges localised, situated and contextual knowledge where the participant practitioner is located as the expert (Marecek, 1989). The crafting of the current paper therefore began when the three authors met to discuss inspiration for, and development of, the infographic. The first author interviewed the other two authors in a subsequent meeting, using a semi-structured interview style. The interviews were then transcribed verbatim and given to the second and third authors to shape a narrative outline from their own accounts. 


\section{Analysis}

Through a reciprocal co-authorship process, the first author facilitated ongoing discussion and feedback to extend the initial outline. This enabled the case study themes to be refined and new key processes in the design of the infographic to be identified. The authors co-produced the story to provide an example of what practitioner-led initiatives can enable. Co-authorship provided a form of validity checking, whereby each member was able to corroborate the representation of experience and community processes that enabled the infographic to be developed.

\section{Findings and Discussion}

The following case study presents processes involved in producing an infographic that aims to increase awareness about emergency preparedness for diverse and marginalised people in Aotearoa/New Zealand, and beyond. The second and third authors' experiences were conceptualised into case study themes that included: the development of the preparedness resource; the importance of multidisciplinary collaboration; working with a media design team; choosing the infographic content; infographic design issues such as colour, materials and logos; public distribution; and national recognition.

\section{Developing Preparedness Material for People with Mobility or Literacy Issues}

Anna-Marie and Angela recognised that there was a need for appropriate emergency preparedness messages for people with mobility or literacy concerns. They searched for international resources on how these people should respond in an emergency situation, such as an earthquake, but were unable to find anything that conveyed a suitable message. They found that resources were wordy, confusing or conveyed a sense of panic and used generic stick figure images in yellow and black. Very few provided information specifically relating to people with a range of mobility issues. Phibbs, Williamson, Woodbury, and Good (2012) had previously investigated disabled community experiences during the Canterbury earthquake sequence of 2010/2011. They argued that research should promote awareness about where to find disability accessible information and that institutions should continue to engage in emergency management planning to assist the disabled.

While Anna-Marie and Angela needed emergency preparedness information suitable for people with mobility issues, they also required a resource that had wider application. After further research it was decided the resource should be picture based so people with limited literacy and English skills could use it. The message needed to be straightforward to engender confidence about knowing what to do in an earthquake and the belief that being prepared for an emergency was easily achievable. Unable to find a resource that fitted these criteria, they decided to create one in collaboration with community, non-governmental and governmental agencies.

Exploring local initiatives, Anna-Marie and Angela found that government departments, including their own, were using pictographs and infographics to display a range of information. Fast growing in popularity because of the potential to reach diverse audiences, infographics transform written and verbal data into simple and accessible graphical layouts. They use stories to engage behaviour, promote knowledge and communicate complex ideas (Cairo, 2013; Tuncali, 2016). Infographics are similar to articles or speeches argued Krum (2014), because they inform and entertain, while also persuading audiences to take action with the information they are presented. Persuasion techniques require that people think about information (O'Keefe, 2008), and a well-designed infographic can encourage thoughtful engagement (Cairo, 2013). A core aim of disaster preparedness messaging is getting people to utilise the information to reduce risk and increase preparedness, such as knowing what to do in an earthquake (Paton \& Johnston, 2001). Anna-Marie and Angela realised this form of communication fitted their purposes and was a suitable tactic to get their preparedness message across.

\section{A Multidisciplinary Collaboration}

Anna-Marie and Angela were given permission by their organisation to begin the project in October 2014. They adopted a collaborative multidisciplinary approach by engaging a wide range of representative stakeholders in the content and design of the resource. Involving stakeholders in community activities can aid in community cohesion, while strengthening social capital and experiences of efficacy, which all contribute to community resilience (Paton \& Johnston, 2001). Initial emails pitching their idea were forwarded to identified stakeholders. All stakeholders responded positively and ongoing consultation occurred with Age Concern, People First, Wellington City Council's Accessibility Advisory Group, Wellington City Council's 
City Housing, Red Cross, Refugee Services, Deaf Aotearoa, Arthritis New Zealand, the Ministry of Civil Defence and Emergency Management, Wellington Region Emergency Management Office, and the Centre for Research, Evaluation and Social Assessment. The latter was an organisation that researched older people and emergencies and that Ana-Marie and Angela had previously worked with.

Human centred design, according to Steen (2011), is when designers and potential users collaborate on the development of a product. Designers must balance the tension between their knowledge and expertise with that of the users, while aiming to match end-users' needs and practices. Anna-Marie and Angela employed this approach and initial meetings with stakeholders included discussions about which key messages to include in the infographic resource. During these meetings, various stories from the Christchurch earthquake were recounted. For example, it was highlighted how people were unable to access hearing aid batteries and experienced difficulties when they could not hear instructions. Embarrassment stopped people from confessing that they could not hear and officials just assumed they understood.

Anna-Marie and Angela highlighted how these kinds of multidisciplinary engagement processes take time, patience and professionalism. Figure 2 is from a PowerPoint presentation that Anna-Marie and Angela shared with stakeholders near the end of the infographic process, on the 3rd of July, 2015. The slide showed various versions of the infographic and highlighted the challenges of stakeholder engagement.

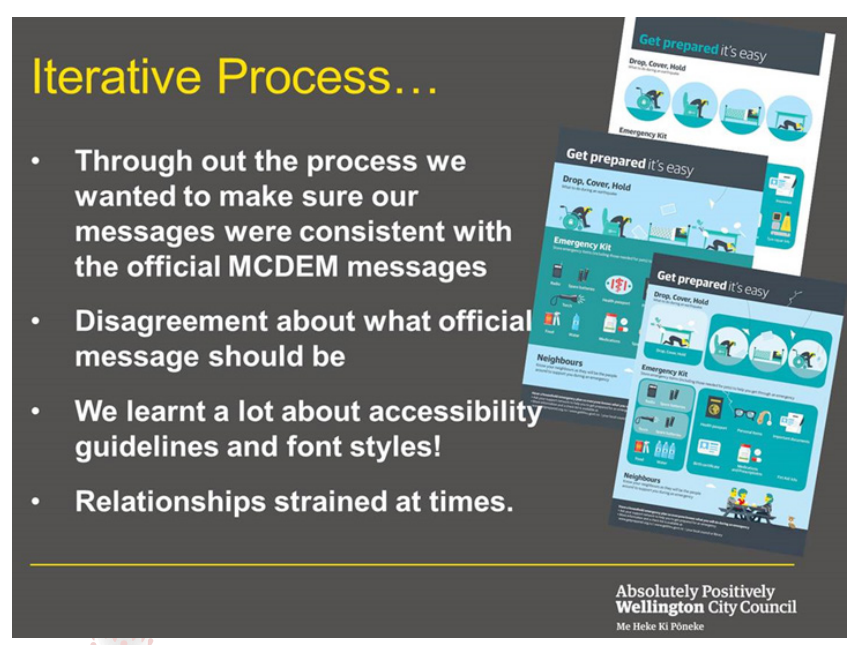

Figure 2. Excerpt from PowerPoint presentation by Anna-Marie and Angela.

\section{Choosing a Graphic Design Company}

A professional graphic design company was initially consulted to work on the infographic. The potential templates looked promising. However, Anna-Marie and Angela needed to get a balance of quotations before deciding on a graphic company, as is prudent with a small budget and public money. A significantly lower quotation from the Wellington City Council in-house design team led to a contract with this team, even though Anna-Marie and Angela were initially keen to work with the external design company. In hindsight, Anna-Marie and Angela realised this was fortuitous because the inhouse designers were easily accessible, professional and patient. Numerous meetings transpired, including several occasions where the graphics team needed to explain the complexity of creating graphics, including the importance of font size and spacing issues, to AnnaMarie and Angela. They had an Easy Read (People First New Zealand Ngā Tāngata Tuatahi, n.d.) guideline for best practice, but applying these suggestions was not straightforward. Designers did not necessarily agree with the best practice approach because it targeted general information materials and did not necessarily convert to specialised or graphic-based documents. Anna-Marie and Angela started listening to their designer team more as trust was built and as they observed the design teams' expertise in action.

\section{Infographic Content}

The Emergency Survival Items and Getaway Kit produced by the Aotearoa/New Zealand Ministry of Civil Defence and Emergency Management (2016b) was used as a guide on what information to include, because it provided a comprehensive list of items required during and following an earthquake. However, condensing the needs of diverse groups into a few key items was complex, especially when comparing items that were needed at home with items needed when evacuating. A lot of consideration was given to particular items that had been suggested as essential in early discussions with stakeholder groups but that were not included in government preparedness messages, such as walking sticks. Stakeholders reported that following the Christchurch earthquakes, even people without mobility-related conditions found the uneven and bumpy streets difficult to manoeuvre and needed walking sticks to get around.

Early iterations of the infographic included hearing aids and medications, as shown in Figure 4 and Figure 5. However, it was decided that it was better to encourage 
people to consider their specific needs, for example medication or prescription glasses. This led to more general infographic labels of "Personal items and documents" and "Medications, prescriptions and first aid kits" as shown in Figure 1. Blankets and sleeping bags were not included because it was assumed people had these items readily available at home. Similarly, although corded landlines are needed if there is an electricity outage, it was decided to include the images of cell phones and chargers shown in Figure 1 as evacuation items, because these are portable and could be taken during evacuation. Anna-Marie and Angela considered having a household plan on the reverse side of the card to include information on family meeting places and how to evacuate. However, this negated the aim of producing a simplistic and accessible infographic. Too much information would have detracted from the main messages.

Representing water storage was also an issue. Ten litre containers are hard to move for some people with disabilities or older adults, so pictures of smaller containers were used. The food containers shown in Figure 1 remained generic, to represent the diversity of food needs, for example baby and animal food. Having too many pictures on the infographic would have made the images too small and more writing would have been required, so only essential images were used. Again, Anna-Marie and Angela drew on the overall objectives for the infographic to help guide which images to include.

Every minute detail of the infographic resource was attended to. With a gap in education material containing information about being outdoors, it seemed important to include an outdoor image on the infographic. The position of the character crouching on the ground facing away from the letterbox, in Figure 1, enabled a subtle preparedness message because facing away protects a person if a letterbox should fall. During the design stages, some debate occurred over the image of the person in bed. One government agency reported that it was safer to lie face down on a bed rather than on your back; however, not all people have the ability to rollover so having an image where the person is protecting their face with a pillow demonstrated how to protect the head in an emergency situation. This image is also displayed in Figure 1. Additionally, this image reflects a range of disaster preparedness literature (for example see Earthquake Country Alliance, 2016; Ministry of Civil Defence \& Emergency Management, 2016c; Southern California Earthquake Center, 2016; Victoria
State Emergency Service, 2016) which reports that it is important to protect your head if confined to a bed.

Understanding the necessity of neighbourliness, because it is often neighbours and local community who provide physical help and emotional support (Gawith, 2011), the infographic shown in Figure 1 also depicts neighbours talking over the fence. This was included to encourage people to know their neighbours before an emergency event. The characters depicted were named after one of the graphic designers and his partner, Ben and Sonya. This use of team member and family names represented the collegiality that eventuated within the design team during the design process. A cat was initially included on the fence line, as shown in Figure 3. However, ongoing public debates about responsible cat ownership in Wellington (for example see Morgan Foundation, 2016) meant that some stakeholders asked to have the cat image removed.

There were ongoing discussions about the design of the characters on the infographic. The team decided to make the characters as gender and ethnically neutral as possible to be culturally inclusive and represent diversity. In this way, some characters were given blue hair, as shown in Figures 1, 2, 4 and 5.

During the design process, drafts were given to intended audiences via face-to-face meetings and emails so that content could be checked, and so that feedback and consultation could occur. At times, stakeholders provided immediate feedback on iterations. At other times, stakeholders consulted with relevant people and communities before responding. Anna-Marie and Angela received conflicting and confusing feedback. For example, some groups wanted images of items falling to denote movement, while others disagreed. It was eventually decided that visual

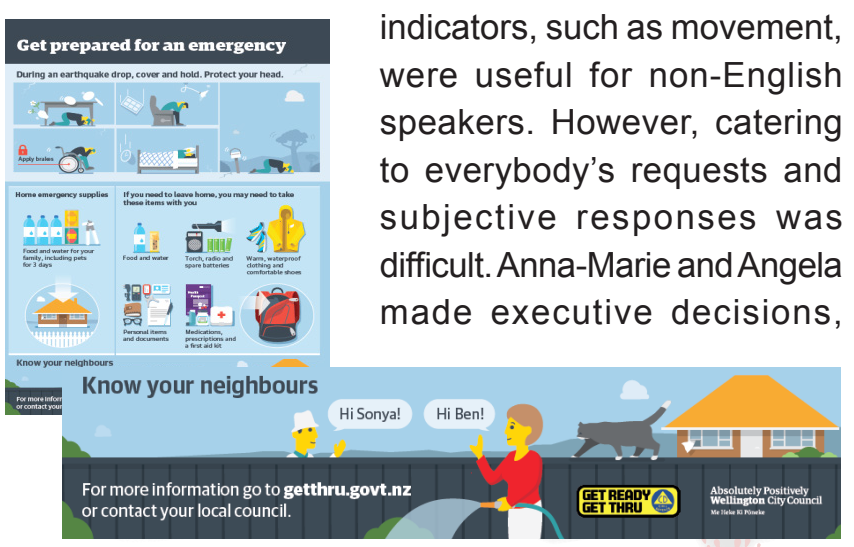

Figure 3. Early iteration of Get Prepared for an Emergency with a cat image. 
knowing that they could not please everyone. They kept returning to their original purpose as a guiding philosophy, and focused on communicating high-level information with the aim of saving lives and preventing injuries.

\section{Colour, Materials and Logos}

As well as testing different emergency preparedness items on the infographic, early iterations involved trialling different colour schemes and graphical design. For examples, see Figure 4 and Figure 5.

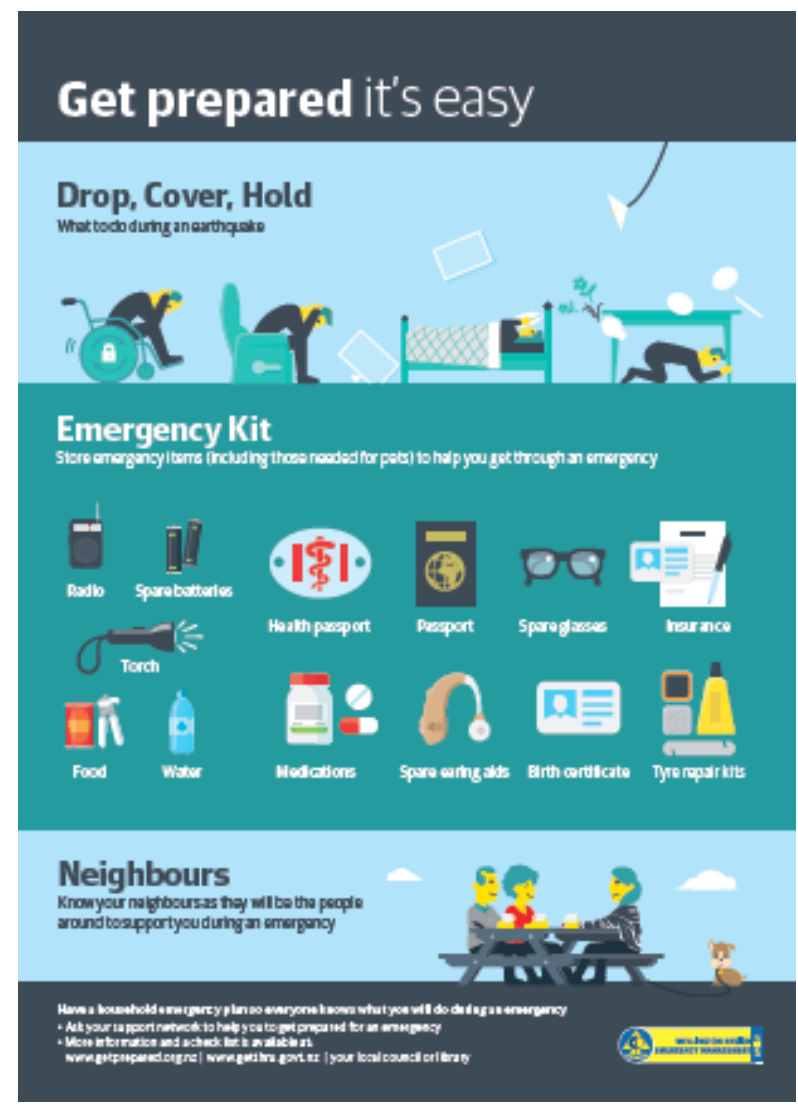

Figure 4. Early iteration of Get Prepared for an Emergency.

Figures 4 and 5 demonstrate different foreground and background colour schemes, shaping and layout of the infographic. Colour contrast between background and foreground colours matters to people with low vision, as does image and wording size. The items shown also vary, for example, Figure 4 has a dog on a lead whereas it has been removed in Figure 5. Likewise, Figures 4 and 5 include different emergency items compared to Figure 1. The overall size of the infographic was also pertinent. Fitting everything onto an A4 sheet and making it visually appealing and clear was a challenge.
Choosing the type of print material was another significant decision. The team considered how people would use the resource. It is common knowledge that consumers easily discard paper materials and the authors wanted the infographic resource to have a sense of permanence. However, the project needed to remain financially manageable and the chosen material needed to be cost efficient. After much deliberation, it was decided to create the resource out of stiff A4 card with magnets attached, so that the resource could be displayed on fridges or other suitable surfaces where it could be often and easily referred to. Larger versions of the resource were also produced for display by groups and organisations, and for people with impaired vision requiring larger print. One of these larger versions is shown in Figure 7.

The logos of the Wellington City Council, the Wellington Region Emergency Management Office and the Ministry of Civil Defence and Emergency Management were included to represent the collaborative approach to the project and helped to give the resource credibility. As argued by O'Keefe (2008), credible sources that engage systematic thinking and convincing arguments related
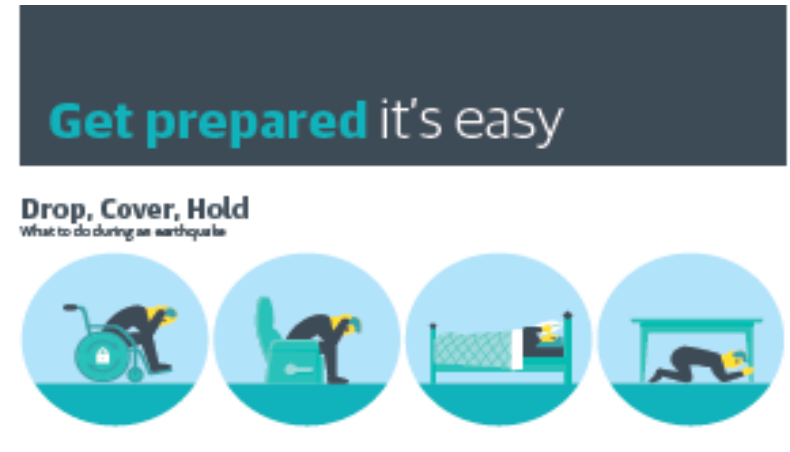

Emergency Kit
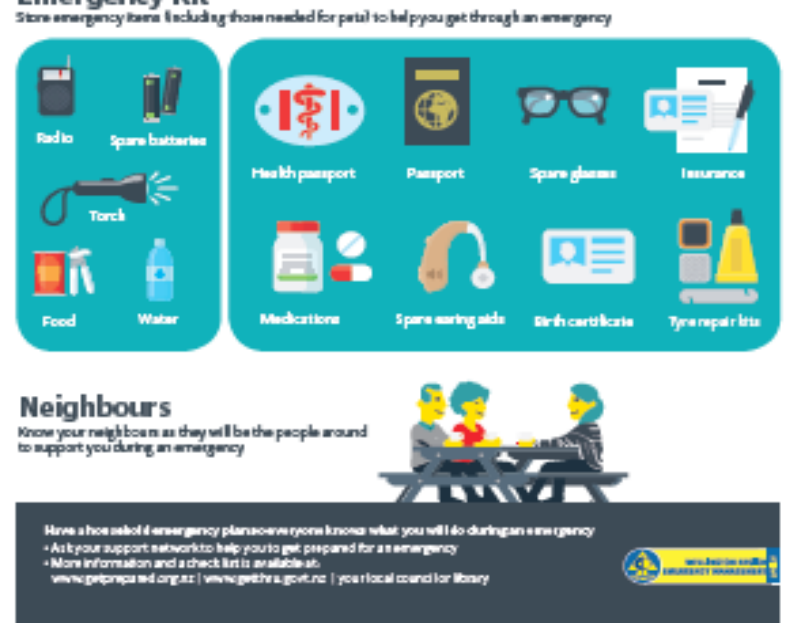

Figure 5. Another early iteration of Get Prepared for an Emergency. 
to the data are important to the process of persuasion. Logos representing trusted sources are shown in Figure 6.

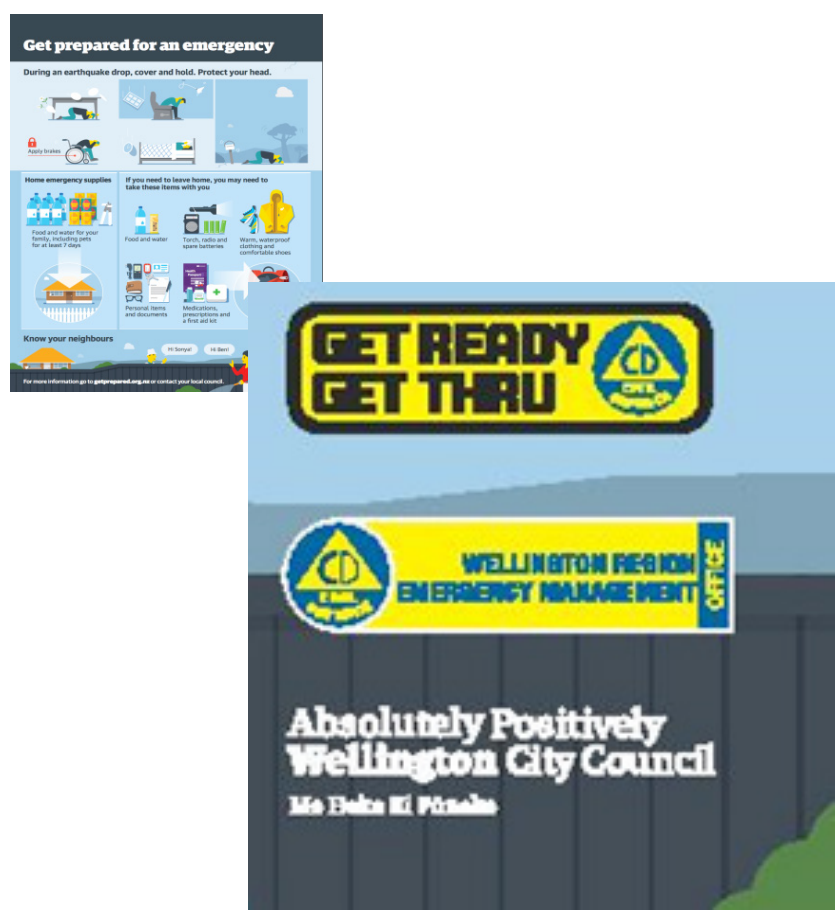

Figure 6. Logos on the bottom right hand corner of the Get Prepared for an Emergency infographic. Reproduced from Get Prepared for an Emergency (p.1) by A. Miller \& A. Rampton. Copyright 2016 by Wellington City Council. Reproduced with permission.

\section{Public Distribution and National Recognition}

The final version of the infographic poster shown in Figure 1 was released in July 2015. The overall time frame for the project was longer than expected. With the first email inquiries sent out in October 2014, Anna-Marie and Angela initially aimed to release the infographic on Aotearoa/New Zealand's national Neighbours Day in late March 2015. Although ambitious, they report that a strict timeline helped focus the work.

While the infographic was being completed, Anna-Marie and Angela published an article about the resource for the June 2015 edition of the Ministry of Civil Defence and Emergency Management magazine, Impact (Miller \& Rampton, 2015). This magazine is distributed to councils and emergency management offices throughout Aotearoa/New Zealand. It provides brief updates on civil defence and emergency management activities and issues and is available online and in press to anyone who is interested in civil defence and emergency management matters. of September 2015 at the CQ Hotel in Wellington. This was an accessibility sensitive hotel that provided services for people with a hearing or visual impairment or other disabilities (CQ Hotel, 2016). Nikki Wagner, Minister for Disability Issues and then Associate Minister of the Christchurch Earthquake Recovery Authority, and Celia Wade-Brown, then Mayor of Wellington, spoke at the launch. The launch was also attended by local councillors, members of the steering group, and members of disability and senior communities.

After the official launch, Anna-Marie and Angela focused their efforts on a distribution plan to reach a wide range of audiences. The infographic was sent to all stakeholders who had assisted in its development as well as other organisations working with culturally and linguistically diverse communities, older people, or people with mobility issues. It was also circulated to organisations such as the local District Health Board, doctors' surgeries, libraries, community centres, and Wellington City Council's City Housing tenants.

The Capital and Coast District Health Board included a version of the infographic in their health passports, a document that holds people's health information in one place, so their information is easily accessible when visiting medical services. This document outlines the type of communication and support a person requires, which is important for people who have hearing impairments, speak English as a second language, or experience some form of dementia (Wellington City Council, 2015). Health passports are also important resources for emergency preparedness. If people need to evacuate suddenly, a health passport has information about medications that can be given to new medical doctors if full health records are not available. As another part of the distribution

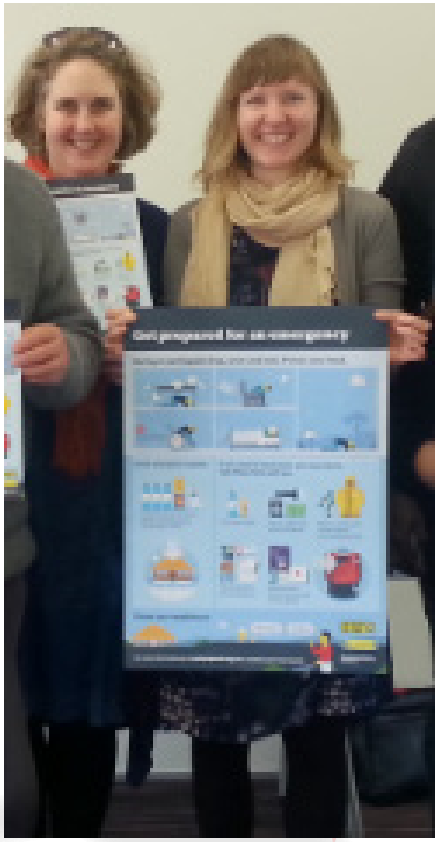

Figure 7. Angela and Anna-Marie during one of their travelling road show presentations of the Get Prepared for an Emergency infographic.

The official infographic launch was held on the 1st

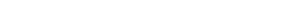


strategy, Anna-Marie and Angela went on what they called a travelling road show. They visited a range of community groups, such as English as a second language classes and retirement villages, to present the poster and to discuss how to respond to and prepare for an emergency.

Feeling satisfied with their substantial efforts in producing the infographic and disseminating this resource, AnnaMarie was surprised when she received a phone call from a Red Cross representative about the misuse of the Red Cross emblem on the infographic first aid kit. The Red Cross representative explained that the Red Cross emblem was first used during World War I when it signified that medical staff were protecting the injured and sick. According to the Red Cross (2016) website, the red cross emblem remains a symbol for the protection of those providing medical care during armed conflict. Consequently, there are regulations surrounding the use of this emblem, and permission to use the emblem must be granted by the Minister of Defence. Anna-Marie and Angela were told to use a green cross for first aid kits as shown on the infographic. They realised it was a lesson in tracking who was checking drafts and how often.

The preparedness infographic has since received national recognition. As shown in Figure 8, the infographic poster received a special commendation in the category of Finalist Best Plain English Document Award from WriteMark Plan English Awards in 2015. WriteMark is an internationally recognised institution that judges the quality of writing for clarity and effect (Writemark Plain English Awards, 2016).

In 2016, Anna-Marie and Angela presented the emergency preparedness infographic poster to a community group in Newtown, Wellington, as part of

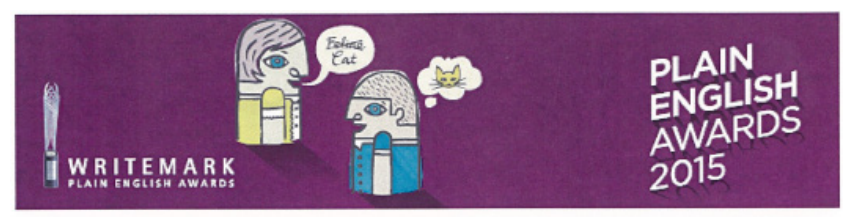

Finalist Best Plain English Document - Public

Wellington City Council - Get prepared for an emergency

Feedback and recommendations from the judging panel

The purpose of this poster is very clear. It presents a really important message, and therefore needs to work well for all citizens, however literate. It absolutely achieves this. It looks like the result of a very good design process. The graphics are entirely relevant and work in perfect tandem with the words. We can't think of any ways to improve it. Excellent work.

We found it hard to judge this poster alongside other entries, as this one has so few words! This makes us think that we need a new 'Best infographic' category in future, so entries like this one can be more fairly judged against other similar entries.

Figure 8. Commendation for Get Prepared for an Emergency infographic. Reproduced from Finalist Best Plain English Document (p.1) by WriteMark. Copyright 2015 by Writemark Plain English Awards. Reproduced with permission. a safety evening. Local Aotearoa/New Zealand Fire Service staff were also speaking at the event. Impressed with the simple and easy to read nature of the poster, the Fire Service has created a similar pictorial resource with few words concerning personal fire safety. They are currently looking at ways of producing and distributing this infographic for the public. While presenting information on the infographic at a conference at a local university, the Director of the Joint Centre for Disaster Research encouraged Anna-Marie and Angela to write an article to share the process of developing the infographic. This was the initial motivation for the current paper.

The infographic has been updated since the initial launch, to reflect current knowledge about water-related preparedness. In May 2016, Wellington Water (2016) updated their recommendations about how much water people should store in preparation for an emergency. The recommended amount shifted from three days to at least seven days, to allow time for alternative methods of mass water distribution, for example: Emergency water tanks filled by water tankers in communities around Wellington. There has also been a written version of the poster produced for people who use screen readers, which are electronic devices that speak written texts out loud.

Various district and regional councils, emergency management groups and community groups from around Aotearoa/New Zealand have contacted Anna-Marie and Angela asking for permission to use the infographic in their different areas. Anna-Marie and Angela are pleased with the infographic's success and strongly endorse the use of this resource. They have even sent out the design files to other councils around Aotearoa/New Zealand who want to make slight adjustments to fit their regions. They only request that the Wellington City Council is acknowledged. Colleagues at the Christchurch City Council are looking to have the infographic translated into other languages for their culturally and linguistically diverse communities. Anna-Marie and Angela continue to work in the community development space. They have ongoing discussions about the infographic with interested parties, including the intended end users.

\section{Conclusion}

Having limited experience in creating a public infographic, Anna-Marie and Angela encountered many hurdles on their way to producing the preparedness infographic. The following section therefore summarises some of 
their key lessons and suggestions for others who may undertake this type of work.

Anna-Marie and Angela advise people to consult with a wide range of groups before commencing the project, especially with intended end-user groups. Consultation enables community engagement, collaboration and shared knowledge production. In this sense, a human centred design approach, that values the intended end-user throughout the process, helps to direct important design decisions, from initial concept options to distribution strategies (Steen, 2011). Each stage of the infographic design should be an iterative process, where decision-making goes through repeated cycles of consultation and in-depth analysis to ensure that the material best fits the intended audience. When, who and how aspects of the drafting process should be carefully documented, so it is clear who is commenting on what versions.

Anna-Marie and Angela also recommend using international best practice guidelines and examples because they can provide evidence bases for how to engage communities of interest and end-users. It is also necessary to identify gaps in knowledge and communication strategies so that any new resources do not repeat previous design or communication errors, and so that the intended resource provides socially responsible and productive information.

It is vital to craft preparedness messages that value diversity, including cultural diversity. While education strategies can continue to provide generic information for large populations, such messages tend to only target majority groups. Disaster preparedness research and educational strategies should also prioritise minority groups. This should include people with a range of specific needs, such as older adults or people with low literacy or physical disabilities. The way that disabled and mobility impaired people are generally underresearched (Kuligowski et al., 2013; Phibbs et al., 2012) is mirrored in the preparedness domain. People with a disability or who are mobility impaired are underresearched in the disaster field and this needs to change (Phibbs et al., 2012).

Practitioners that work tirelessly to engage and support local communities at the local level also need to be recognised. The infographic resource, Get Prepared for an Emergency, produced by two communityfocused Wellington City Council workers has seen preparedness messages reach those who had initially been inaccessible and overlooked. The importance of this work and how it is achieved needs to be communicated, understood and commended.

\section{References}

Basnyat, B., Dalton, H. R., Kamar, N., Rein, D. B., Labrique, A., Farrar, J., . . . on behalf of 21 signatories (2015). Nepali earthquakes and the risk of an epidemic of hepatitis E. The Lancet, 385, 2572-2573. doi:10.1016/S01406736(15)61110-2

Cairo, A. (2013). The functional art: An introduciton to information graphics and visualization. Berkeley, CA: New Rider.

CQ Hotel. (2016). Accessible facilities at CQ Hotels Wellington. Retrieved from www.hotelwellington.co.nz/accessibility/ cq-accessibility.htm

Earthquake Country Alliance (2016). How to protect yourself during an earthquake. Retrieved from www. earthquakecountry.org/dropcoverholdon/\#disability

Flyvbjerg, B. (2011). Case study. In N. K. Denzin \& Y. S. Lincoln (Eds.), The sage handbook of qualitative research (4 ed. pp. 301-316). London, UK: Sage.

Frumkins, H. (2011). Bumps on the road to preparedness. American Journal of Preventive Medicine, 40, 272-273. doi:10.1016/j.amepre.2010.11.001

Gawith, L. (2011). How communities in Christchurch have been coping with their earthquake. New Zealand Journal of Psychology, 40, 121-130. www.psychology.org.nz/ publications-media/new-zealand-journal-of-psychology/

GNS Science Te Pū Ao (2016). Plate tectonics. Retrieved from www.gns.cri.nz/Home/Our-Science/Earth-Science/ Plate-Tectonics

Hancox, G. T., Perrin, N. D., Archibald, G. C., Misra, S., \& Cousins, W. J. (2013). Reconnaissance report on liquefaction effects and landslides caused by the M 6.5 Cook Strait earthquake of 21 July 2013, New Zealand. Retrieved from www.gns.cri.nz/static/pubs/2013/SR\%20 2013-042.pdf

Hays, P. A. (2004). Case study research. In K. deMarrais \& S. D. Lapan (Eds.), Foundations for research: Methods of inquiry in education and the social sciences (pp.217-234). New Jersey, NY: Lawrence Erlbaum Associates.

Health and Disability Commissioner Te Toihau Hauora Hauātanga (2016). Health passport. Retrieved from www. hdc.org.nz/about-us/disability/health-passport

Johnston, D., Standring, S., Ronan, K., Lindell, M., Wilson, T., Cousins, J., . . . Bissell, R. (2014). The 2010/2011 Canterbury earthquakes: context and cause of injury. Natural Hazards, 73, 627-637. doi:10.1007/s11069-0141094-7

Krum, R. (2014). Cool infographics: Effective communication with data visualization and design. Indianapolis, IN: Wiley \& Sons.

Kuligowski, E., Peacock, R., Wiess, E., \& Hoskins, B. (2013). Stair evacuation of older adults and people with mobility impairments. Fire Safety Journal, 62, 230-237. doi:0.1016/j.firesaf.2013.09.027

Marecek, J. (1989). Introduction. Psychology of Women Quarterly, 13, 367-377. doi:10.1111/j.1471-6402.1989. tb01008.x 
Miller, A.-M., \& Rampton, A. (2015). Pictorial emergency preparedness poster. Impact, 56, 11. www.civildefence. govt.nz/resources/impact/

Ministry of Civil Defence \& Emergency Management (2015). Drop, cover and hold is still the right action to take. Wellington, Aotearoa/New Zealand: Ministry of Civil Defence and Emergency Management.

Ministry of Civil Defence \& Emergency Management (2016a). Earthquake. Retrieved from http://getthru.govt.nz/ disasters/earthquake

Ministry of Civil Defence \& Emergency Management (2016b). Emergency survival items and getaway kit. Retrieved from www.civildefence.govt.nz/assets/Uploads/publications/ consistent-messages-part-A-emergency-survival-kit.pdf

Ministry of Civil Defence \& Emergency Management (2016c). People with disabilities or special requirements. Retrieved from www.getthru.govt.nz/how-to-get-ready/people-withdisabilities/

Ministry of Civil Defence and Emergency Management (2015). Guide to the National Civil Defence Emergency Management Plan 2015. Wellington, Aotearoa/New Zealand: Ministry of Civil Defence and Emergency Management.

Morgan Foundation (2016). That little ball of fluff you own is a natural born killer. Retrieved from https://garethsworld. com/catstogo/\#.V6cQPpN95E4

New Zealand Police Nga Pirihimana o Aotearoa (2012). Christchurch earthquake: List of deceased. Retrieved from www.police.govt.nz/major-events/previous/christchurchearthquake

O'Keefe, D. J. (2008). Elaboration likelihood model. International encyclopedia of communication, 4, 14751480. www.communicationencyclopedia.com/public/

Paton, D. (2003). Disaster preparedness: A socialcognitive perspective. Disaster Prevention and Management: An International Journal, 12, 210-216. doi: 10.1108/09653560310480686

Paton, D., \& Johnston, D. (2001). Disasters and communities: vulnerability, resilience and preparedness. Disaster Prevention and Management: An International Journal, 10, 270-277. doi: 10.1108/EUM0000000005930

People First New Zealand Ngā Tāngata Tuatahi (n.d.). Make it clear: A guide to making it easy read information. Retrieved from www.peoplefirst.org.nz/news-and-resources/easyread-resources/

Phibbs, S. R., Williamson, K. J., Woodbury, E., \& Good, G. A. (2012). Issues experienced by disabled people following the 2010-2011 Canterbury earthquake series: Evidence based analysis to inform future planning and best practice guidelines for better emergency preparedness. Retrieved from www.gns.cri.nz/static/pubs/2012/S\%202012-040.pdf

Red Cross. (2016). Using the Red Cross emblem. Retrieved from www.redcross.org.nz/about-us/centenary/worldwar-i/using-red-cross-emblem/

Southern California Earthquake Center (2016). Protect yourself during earthquake shaking - drop, cover, and hold on. Retrieved from www.earthquakecountry.org/ roots/step5.html

Statistics New Zealand Tatauranga Aotearoa (2016). Statistics New Zealand. Retrieved from www.stats.govt.nzl

Steen, M. (2011). Tensions in human-centred design. CoDesign, 7, 45-60. doi:10.1080/15710882.2011.563314
Tuncali, E. (2016). The Infographics which are designed for environmental issues. Global Journal on Humanites \& Social Sciences , 3, 14-19. http://sproc.org/ojs/index.php/ pntsbs/article/view/272/pdf

Tuohy, R., \& Stephens, C. (2012). Older adults' narratives about a flood disaster: Resilience, coherence, and personal identity. Journal of Aging Studies, 26, 26-34. doi:10.1016/j. jaging.2011.06.002

Victoria State Emergency Service (2016). What to do in an earthquake. Retrieved from www.ses.vic.gov.au/get-ready/ quakesafe/what-to-do-in-an-earthquake

Wellington City Council (2015). Emergency preparedness poster officially launched. Retrieved from http://wellington. govt.nz/services/community-and-culture/community-newsand-events/archived-articles/emergency-preparednessposter-released

Wellington City Council (2016). Get prepared for an emergency. Wellington, Aotearoa/New Zealand: Wellington City Council.

Wellington Water (2016). Water supply resilience - gathering steam: Recent coverage compels action. Wellington, Aotearoa/New Zealand: Wellington Water.

WriteMark Plain English Awards (2016). Who's the clearest of them all? Retrieved from www.plainenglishawards.org.nz

Wurman, R. S. (2000). Information anxiety. New York, NY: Que.

Yin, R. K. (2014). Case study research: Design and methods (5th ed.). Los Angeles, CA: Sage. 